Introduction

\title{
Cognitive attitudes and values in science
}

When citing this paper, please use the full journal title Studies in History and Philosophy of Science

This special section grew out of a workshop on "Cognitive Attitudes and Values in Science" that was held at the University of Notre Dame in June 2013. Although each of the papers included in this volume approaches the topic in different ways, they all explore the central theme of how careful attention to the range of cognitive attitudes available to scientists and the differences between them might help to generate more careful and insightful ways of thinking about the appropriate roles for values in science. This introduction to the special section begins with a brief overview of recent literature on cognitive attitudes and its relevance for thinking about values in science. The second part provides a summary of the articles in this section, highlighting the distinctive contribution that each makes to discussions about the central theme.

Cognitive attitudes are evaluative responses directed toward some sort of content, such as hypotheses, theories, models, propositions, or other forms of representation. While belief and associated probabilistic judgments such as degrees of belief (levels of confidence or credence) have traditionally received the lion's share of attention from philosophers of science and epistemologists, recent scholarship has drawn attention to the nuance and variety of epistemic and practical attitudes that real scientists adopt in the course of inquiry (e.g., Elliott, 2013; Elliott \& McKaughan, 2014; McKaughan, 2007, 2008, 2012; van Fraassen, 1980; Wray, 2001). In addition to believing, there are a variety of other forms of qualified, partial and tentative attitudes that play an important role in scientific practice. Intentional mental states of this sort, or the speech acts used to express them, are sometimes marked by attitude verbs such as accept, assume or presuppose, hypothesize or conjecture, predict, speculate, guess, suspect, entertain, judge to be worthy of pursuit, and so on.

For example, consider the literature on belief and acceptance. $C$. S. Peirce is among the earliest to insist on a principled distinction between belief and scientific acceptance (Peirce, 1898, 56), but the account in Jonathan Cohen's monograph, An Essay on Belief and Acceptance (1992), is among the most influential today. Cohen builds a number of conditions into his accounts of belief and acceptance, some more controversial than others. One of the ways that Cohen contrasts these two attitudes turns on the issue of voluntary control. Whereas believing a proposition, $p$, is often regarded as for the most part involuntary - largely a matter of passively finding oneself with the conviction that $p$ is the case - acceptance is explicitly defined as a mental act that is under one's direct voluntary control. To accept that $p$, in this sense, is to adopt or commit oneself to a policy of treating $p$ (and what one concedes to be deductive consequences that follow from $p$ ) as true in one's conscious reasoning whether or not one feels $p$ to be true. Keith Frankish gives an example, which we can borrow independently of the particularities of his own view of acceptance, of a situation in which what one believes and what one accepts as a basis for action can come apart:

Suppose I believe that the gun in my desk drawer is unloaded. And suppose I am now offered a small sum of money for taking the weapon, aiming it at the head of a loved one, and pulling the trigger. In deciding whether or not to accept this offer, I might, quite reasonably, refrain from relying on the proposition that the gun is unloaded (Frankish, 2004, 134-135).

Clearly, one can believe that the gun is loaded without accepting it as a premise in one's deliberative reasoning or actions and one can accept that it is loaded without believing that it is. In other situations, such as the choice to trust someone who has let one down in the past or the decision of a rescue team to continue the search for workers who were trapped in a collapsed mine, practical considerations might lead one to accept a proposition as a basis for action that one doesn't have good reason to believe (McKaughan, 2013).

This strategy for distinguishing between belief and acceptance locates the latter more clearly in the domain of action. There have been many other attempts to employ "belief" and "acceptance" to distinguish between two kinds of assent (see, for example, Alston, 1996; Bratman, 1992; Buckareff 2004; Cohen, 1989, 1992; da Costa \& French, 1993, 2003; Engel, 1998, 1999, 2000; Frankish, 2004; Harman, 1986; Kaplan, 1981, 1996; Maher 1990, 1992, 1993; Lehrer, 1983, 2000; Levi, 1997; Perry, 1980; Stalnaker, 1984; Ullman-Margalit and Margalit, 1992; van Fraassen, 1980; and Velleman, 2000). Indeed, the fact that authors use these terms to mark a bewildering variety of different distinctions, in very different ways, and for such different purposes, is one indication 
of the need for a more uniform and finely-grained analysis of cognitive attitudes. But the analysis that we have provided here already highlights an important point for those who are interested in the connection between cognitive attitudes and values in science. To the extent that acceptance is voluntary and can be oriented around concerns that are not limited solely to the aim of forming an opinion about what is true, practical considerations can clearly be relevant to acceptance in ways that, at least arguably, they are not relevant to belief. In the gun-in-one's-desk-drawer example, factors such as one's values and tolerance for risk legitimately contribute, alongside one's epistemic opinion, to one's decision whether or not to accept that the gun is unloaded. Similarly, in scientific contexts where the acceptance of a model or theory can have important effects on society, a range of non-epistemic values may also have an important role to play (Elliott and Willmes 2013).

Such considerations raise a host of questions that we would like to see addressed in the years ahead. Might, for example, disputes over the proper roles for non-epistemic values in responding to situations of underdetermination be clarified by analyzing the range of cognitive attitudes available to scientists in such situations (e.g., belief $v s$. acceptance) and the sorts of values that are relevant when adopting particular attitudes? Might the literature on values in science be strengthened by reflecting on the cognitive attitudes that scientists adopt toward simplified models or toward technoscientific artifacts and the sorts of epistemic, ethical, and pragmatic values that promote the aims associated with those attitudes? Is it important to clarify what cognitive attitudes scientists are adopting when they propound claims as voices of authority in policy contexts, given that different sorts of values may become relevant to their work as a result? With these sorts of issues in mind, the workshop's call for papers invited contributions to the following sorts of questions:

(1) What are the major cognitive attitudes that scientists have employed and that they could employ? How should these attitudes be individuated, defined, and characterized?

(2) Which cognitive attitudes are most appropriate to take toward particular products of scientific activity (e.g., models, hypotheses, technoscientific objects, claims made for regulatory purposes, etc.)?

(3) What criteria are available for evaluating whether the cognitive attitudes adopted by scientists in particular contexts are appropriate?

(4) What categories of values (e.g., epistemic, ethical, and pragmatic) promote the aims associated with particular cognitive attitudes?

(5) In what ways can and should scientists clarify their cognitive attitudes in scientific papers, in assessments used for policy purposes, and in communication with the public?

(6) How can the analysis of cognitive attitudes promote more sophisticated approaches to delineating the proper roles for values in science?

(7) How can the analysis of cognitive attitudes promote more sophisticated communication between scientists, policy makers, and members of the public?

Much work remains to be done in order to be in a good position to answer such questions. But we believe that each of the articles included in this special section raises, in a distinctive way, fundamental issues that illustrate how careful attention to cognitive attitudes can contribute to the literature on how values appropriately influence science.

The first article, by Matthew Brown, draws on John Dewey's account of scientific reasoning in order to challenge those who attempt to defend the ideal of value-free science by making a distinction between belief and action. As Brown correctly observes, proponents of the value-free ideal often maintain that only evidential considerations (i.e., considerations that bear on the likely truth or falsity of a theory) are relevant to epistemic evaluation, while they concede that non-evidential considerations are relevant to decisions about how to act, including the use or application of a theory. As part of his attempt to undercut this approach to defending the value-free ideal from a Deweyian perspective, Brown provides a particularly clear exposition of Dewey's epistemological framework. Brown claims that Dewey's epistemology is grounded in the concept of inquiry. Individuals engage in inquiry to resolve problematic situations. The conclusion of inquiry is a judgment, which is a decision to act in a particular manner in order to resolve the situation. Importantly, Dewey holds that all judgments are judgments of practice, which means that they "propose a course of action, rather than (merely) describing a state of affairs" (Brown, 2015). Therefore, for Dewey the classic equation of knowledge with justified true belief is replaced by the equation of knowledge with true judgment. Moreover, to say that a judgment is true is to say that it resolves the problematic situation that it is designed to address.

As Brown explains, Dewey's innovative epistemological framework yields an intriguing account of the cognitive attitudes that scientists employ. For Dewey, scientists employ two major cognitive attitudes. First, they affirm propositions. It is crucial to recognize that Dewey defined propositions in a very idiosyncratic manner, as symbolic representations that play an intermediate role in inquiry. Thus, to affirm a proposition for Dewey is to regard it as worthy of pursuit, to accept it tentatively as a representation worthy of further investigation. Second, Dewey claims that scientists assert judgments. We have seen that judgments are the final outcome of inquiry, and thus the attitude of assertion involves the stronger conclusion that a judgment is true (in the sense that it resolves a problematic situation). But the crucial feature of this framework is that Dewey has replaced the traditional cognitive attitude of belief with the attitude of assertion, and non-epistemic values are relevant to this attitude insofar as they help to determine whether a particular judgment resolves a problematic situation successfully.

Brown concludes that Dewey's framework challenges the "wedge" argument that various authors have used to maintain science's value-freedom. These authors acknowledge that nonepistemic values can play an appropriate role in scientific evaluations aimed at deciding how to act, but they insist that these values should not influence scientific evaluations directed at deciding what to believe (Giere, 2003; Mitchell, 2004). Kevin Elliott and David Willmes (2013) have turned this line of argument on its head and used it as a way of defending roles for non-epistemic values in science, insofar as they argue that cognitive attitudes other than belief are primary in most scientific practice. Brown takes their line of argument a step further and rejects traditional conceptions of belief and truth altogether. According to his alternative Deweyian account of the cognitive attitudes that scientists do and should adopt, there are no domains of science that must remain systematically value-free. Dewey's epistemology not only provides a challenging alternative to typical philosophical accounts of knowledge but, Brown argues, it supplies an enlightening description of different cognitive attitudes that play a role in scientific inquiry. Thus, it provides many points of potential interest even for readers who remain unconvinced by Brown's criticism of the belief-act distinction or by Dewey's overall epistemological framework.

Angela Potochnik approaches the role of values in science by revisiting the aims of science. She argues that different aims require different scientific products (i.e., models or theories) and provide 
different roles for social values. Starting from the fact that idealization is exceptionally widespread in science, Potochnik argues that this feature of science would fit more comfortably with the view that understanding, not truth, is the ultimate epistemic aim of science. Although Potochnik does not define the notion of truth that she targets, in contrast to Brown's discussion of Dewey, she seems to have a more traditional idea of correspondence or fit between representation and reality in view. As Potochnik points out, scientific models are often recognizably far from the truth. The contrast between understanding and truth raises questions about whether understanding requires grasping relevant truths and, since truth is a condition on traditional analyses of knowledge, whether on Potocknik's account, understanding can fall short of knowledge. Following Catherine Elgin (2004), Potochnik takes it that current scientific models regularly provide understanding despite significant departures from the truth. As Potochnik points out, this argumentative move makes sense only when one is clear about cognitive attitudes - it makes sense to accept false models as sources of increased understanding, but it would not make sense to believe in their truth (Potochnik, 2015). It is worth considering whether Potochnik's account would set aside not only truth but also empirical adequacy as the epistemic aim of science. If so, her argument might be even more provocative than it initially appears, considering that even classical instrumentalists take fit with the available data as an important, perhaps even rock bottom, criterion for success.

In addition to arguing that understanding, rather than truth, is the primary epistemic aim of science, Potochnik argues that science has many non-epistemic aims as well as epistemic ones. This pluralism with respect to overall aims might be thought to sit uneasily with a defense of the idea that understanding is the sole epistemic aim of science. However, her crucial point is that, due to the complexity of the natural world, different aims frequently clash, insofar as models that promote the achievement of one aim (e.g., prediction) often do not promote the achievement of other aims (e.g., understanding). In fact, even the achievement of a single aim, such as understanding, can require different sorts of models depending on which features of a phenomenon one is trying to understand. Once again, Potochnik notes that being clear about cognitive attitudes is crucial for making sense of these different aims, insofar as scientists can accept models or theories for some purposes but not others (Elliott and Willmes 2013).

The upshot of Potochnik's account is that science is a very human-focused endeavor-it is focused on promoting human understanding and other human aims. Therefore, on her account, human values have a significant role to play in evaluating the adequacy of scientific products. For example, she claims: "Different research agendas lead to different emphases and parsings of the causal space and, as a result, vastly different varieties of understanding" (Potochnik, 2015). In other words, depending on the values of society or the scientific community, science aims at different sorts of understanding of a particular domain. Based on these different aims, different models or theories become worthy of acceptance, and different criteria are needed for evaluating them (see also Elliott \& McKaughan, 2014).

Daniel Steel's contribution to the section approaches the topic of values in science from within a more traditional framework. He revisits the classic debate between Richard Rudner and Robert Jeffrey in the 1950s. According to Rudner's famous argument from inductive risk, scientists have to make value judgments insofar as they have to decide how much evidence to demand in order to accept hypotheses (Rudner, 1953). Jeffrey (1956) responded that scientists should not be in the business of accepting hypotheses; instead, they should provide the probability of the hypotheses and let others make the value judgments about whether or not to accept them. Steel clarifies that the crucial issue at stake between Rudner and Jeffrey is what cognitive attitude to adopt toward these probabilities: are they degrees of belief (as Jeffrey contends, along with most Bayesians) or are they degrees of acceptance (as Rudner and Steel suggest). This issue is significant, because if the probabilities of hypotheses are accepted (rather than being believed in a passive fashion), then Rudner's argument from inductive risk cannot be escaped. On Rudner's view, scientists have to make value judgments even when deciding what probabilities to assign to hypotheses.

Steel clarifies the Bayesian argument for treating cognitive judgments about the probabilities of hypotheses (or, as he calls them, "personal probabilities") as objects of belief, and then he argues that they are more appropriately treated as objects of acceptance. The question at issue is whether we should understand personal probabilities as items that one passively-and for the part involuntarily-finds oneself with, or does one instead choose to adopt them (or not) through a voluntary mental act or decision? Although Bayesians do not speak with a unified voice on this issue, Steel points out that Bayesians typically opt for the former. They hold that the criterion for deciding whether an action is rational is to use personal probabilities as inputs to determine whether the action maximizes expected utility. Considering that acceptance is a type of decision, it would "put the cart before the horse" for a Bayesian to accept personal probabilities. As Steel puts it, the accepted personal probabilities would end up being "parasitic" on already existing degrees of belief that fed into the expected utility calculation (Steel, 2015). Thus, the accepted personal probabilities would be redundant (if they were identical to the degrees of belief) or deceptive (if they were distinct from the degrees of belief).

Steel responds to the Bayesian argument by pointing out that degrees of belief are typically vague and incomplete, and in some circumstances one can recognize that one's own degrees of belief are unreasonable, perhaps owing to an irrational phobia or bias. Thus, accepted personal probabilities need not be either redundant or deceptive. He points to literature from cognitive psychology indicating that people's preferences are often imprecise and incomplete, and they construct more precise preferences only in specific decision contexts. Thus, to the extent that degrees of belief are defined in terms of people's preferences, it makes sense to think of them as imprecise and incomplete as well. Similarly, psychological evidence indicates that people's degrees of belief are often generated by irrational heuristics and biases. On Steel's view, personal probabilities are better construed as consciously endorsed normative judgments about the betting quotients it is reasonable to accept in a given context. Therefore, Steel argues that it is entirely reasonable for scientists to accept personal probabilities that are distinct from their potentially vague, incomplete, and unreasonable degrees of belief. And to the extent that scientists accept these personal probabilities, Steel suggests that they need to make value judgments about whether the potential errors associated with their chosen probabilities are acceptable. Thus, based on Steel's careful analysis of cognitive attitudes, he concludes that value judgments penetrate into the heart of science-legitimately, and indeed inescapably, factoring into assessments of the degrees of confirmation for hypotheses.

Hugh Lacey argues that the proper roles for values in science can be clarified by developing more detailed distinctions between cognitive attitudes within the general category of acceptance (see Cohen, 1992; Elliott and Willmes, 2013). He distinguishes the attitudes of holding, adopting, and endorsing hypotheses or theories, and he argues that these attitudes are employed at different logical "moments" of scientific activity. For Lacey, to hold a claim $p$ is to treat it as belonging to the stock of established scientific 
knowledge. His account of what it means to be part of this stock is extremely demanding. He requires that all objections raised against $p$ have been addressed and that no further objections are reasonably anticipated. The attitude of adopting a claim requires far less evidence. To adopt a claim $p$ is to prefer $p$ to its competitors "for the sake of giving direction to on-going research" in a particular area (Lacey, 2015). Whereas Lacey does not think that ethical and social values have a role to play in assessing whether a claim is worthy of being held, he does think that they can be relevant to adopting claims. For example, if a particular theory has better conceptual resources than others for addressing phenomena that are of significant ethical or social interest, then the theory might be adopted in part for those ethical or social reasons.

Lacey argues that the cognitive attitude of endorsement becomes relevant when scientists are engaged in applying research. At this point, they have to evaluate claims about the risks and benefits of implementing particular innovations. He holds that to endorse one of these claims, $p$, is "to treat $p . .$. as being supported by evidence that is sufficiently strong that the legitimacy of courses of action ... informed by it, should not be challenged on the ground that $p$ has insufficient empirical support" (Lacey, 2015). Lacey holds that ethical and social value judgments are highly relevant to decisions about endorsing hypotheses, because they determine the ethical seriousness of accepting them incorrectly, and therefore the amount of empirical support needed to justify endorsing them (Douglas, 2009).

One of Lacey's central conclusions is that the distinction between endorsing and holding hypotheses is crucial for maintaining proper regulatory policy. For example, Lacey holds that when the scientific community endorses a hypothesis about the risks associated with new technologies, such as GMOs, it does not carry the same weight as if they were holding the hypothesis. Because endorsements rest on value judgments, he suggests that the scientific community's endorsements should be given significant weight but should not be treated as decisive when deliberating about technological risks. Instead, he calls for broader, democratic deliberations about which risk claims should be endorsed. Lacey argues that this sort of democratic deliberation is particularly important, given that the scientific community has a tendency to endorse claims about the risks of GMOs based on capitalist values that downplay or ignore concerns about the social consequences of emerging technologies on marginalized communities.

With this introduction we present four articles for the reader's consideration. These contributions indicate that questions about cognitive values can inform a number of important debates. First, they can help determine whether and in what sense it is reasonable to claim that science is value free. Second, they can help to clarify the aims of scientific inquiry and the roles that values play in achieving those aims. Third, they can help to address fundamental interpretive issues at the core of confirmation theory, which in turn have significance for understanding inductive risk and the roles of value judgments in basic judgments of subjective probability. Fourth, they can help to clarify policy debates and the legitimate roles for values in them. Without pretending to offer the final word on any of these matters, together these contributions indicate that a more nuanced and finely grained understanding of the role that various cognitive attitudes play in scientific practice is likely to continue to enrich the literature on how values influence science.

\section{References}

Alston, W. P. (1996). Belief, acceptance, and religious faith. In J. Jordan, \& D. HowardSnyder (Eds.), Faith, freedom, and rationality. Lanham: Lowman \& Littlefield Publishers, Inc.
Bratman, M. (1992). Practical reasoning and acceptance in a context. Mind, 101, 1-15. (reprinted in Michael Bratman (1999) Faces of Intention: Selected Essays on Intention and Agency. Cambridge: Cambridge University Press, 15-34).

Brown, M. J. (2015). John Dewey's pragmatist alternative to the belief-acceptance dichotomy. Studies in History and Philosophy of Science. http://dx.doi.org/ 10.1016/j.shpsa.2015.05.012.

Buckareff, A. A. (2004). Acceptance and deciding to believe. Journal of Philosophical Research, 29, 173-190.

Cohen, L. J. (1989). Belief and acceptance. Mind, XCVIII(391), 367-389.

Cohen, L. J. (1992). An essay on belief and acceptance. Oxford: Oxford University Press.

da Costa, N. C. A., \& French, S. (1993). Towards an acceptable theory of acceptance In S. French, \& H. Kamminga (Eds.), Correspondence, invariance and heuristics (pp. 137-158). Dordrecht: Reidel.

da Costa, N. C. A., \& French, S. (2003). Science and partial truth: A unitary approach to models and scientific reasoning. Oxford: Oxford University Press.

Douglas, H. (2009). Science, Policy, and the Value-Free Ideal. Pittsburgh: University of Pittsburgh Press.

Elgin, C. Z. (2004). True enough. Philosophical Issues, 14, 113-131.

Elliott, K. C. (2013). Douglas on values: From indirect roles to multiple goals. Studies in History and Philosophy of Science, 44, 375-383.

Elliott, K. C. and Willmes, D. (2013). "Cognitive attitudes and values in science." Philosophy of Science 80 Philosophy of Science (PSA: Proceedings of the Biennial Meeting of the Philosophy of Science Association), 80, 807-817.

Elliott, K. C., \& McKaughan, D. J. (2014). Non-epistemic values and the multiple goals of science. Philosophy of Science, 81, 1-21.

Engel, P. (1998). Believing, accepting, and holding-true. Philosophical Explorations, II(1), 140-151.

Engel, P. (1999). Dispositional belief, assent, and acceptance. Dialectica, 53(3/4), 211 226.

Engel, P. (2000). Believing and accepting. Philosophical Studies Series. Dordrecht: Kluwer Academic Publishers.

van Fraassen, B. C. (1980). The scientific image. Oxford: Oxford University Press.

Frankish, K. (2004). Mind and supermind. Cambridge: Cambridge University Press.

Giere, R. (2003). A new program for philosophy of science. Philosophy of Science, 70 , $15-21$.

Harman, G. (1986). Change in view: Principles of reasoning. Cambridge: The MIT Press.

Jeffrey, R. (1956). Valuation and acceptance of scientific hypotheses. Philosophy of Science, 23, 237-246.

Kaplan, M. (1981). A Bayesian theory of acceptance. The Journal of Philosophy, 78 305-330.

Kaplan, M. (1996). Decision theory as philosophy. Cambridge: Cambridge University Press.

Lacey, H. (2015). 'Holding' and 'endorsing' claims in the course of scientific activities. Studies in History and Philosophy of Science. http://dx.doi.org/10.1016/ j.shpsa.2015.05.009.

Lehrer, K. (1983). Belief, acceptance, and cognition. In H. Parret (Ed.), On believing. De la croyance (pp. 172-183). Berlin: de Gruyter.

Lehrer, K. (2000). Theory of knowledge. Boulder: Westview Press.

Levi, I. (1997). The covenant of reason: Rationality and the commitments of thought. Cambridge: Cambridge University Press.

Maher, P. (1990) “Acceptance without belief," Philosophy of Science (PSA: Proceedings of the Biennial Meeting of the Philosophy of Science Association), 1, 381-392.

Maher, P. (1992). "Acceptance in Bayesian Philosophy of Science," Philosophy of Science (PSA: Proceedings of the Biennial Meeting of the Philosophy of Science Association), 153-160.

Maher, P. (1993). Betting on theories. Cambridge: Cambridge University Press.

McKaughan, D. J. (2007). Toward a Richer vocabulary for epistemic attitudes: Mapping the cognitive landscape. University of Notre Dame. PhD Dissertation.

McKaughan, D. J. (2008). From ugly duckling to swan: C. S. Peirce, abduction, and the pursuit of scientific theories. Transactions of the Charles S. Peirce Society 44(3), 446-468.

McKaughan, D. J. (2012). Speech acts, attitudes, and scientific practice: Can Searle handle assuming for the sake of hypothesis? Pragmatics and Cognition, 20(1), 88-106.

McKaughan, D. J. (2013). Authentic faith and acknowledged risk: Dissolving the problem of faith and reason. Religious Studies, 49(1), 101-124.

Mitchell, S. (2004). The prescribed and proscribed values in science policy. In P. Machamer, \& G. Wolters (Eds.), Science, Values, and Objectivity (pp. 245255). Pittsburgh: University of Pittsburgh Press.

Peirce, C.S. (1898). "The First Rule of Logic," The Essential Peirce: Selected Philosophical Writings, Volume 2 (1893-1913), edited by Nathan Houser, Christian Kloese and The Peirce Edition Project. Bloomington: Indiana University Press, 1998.

Perry, J. (1980). Belief and acceptance. In P. French, T. Uehling, \& H. Wettstein (Eds.), Midwest studies in philosophy, 5 (pp. 533-542). Minneapolis: University of Minnesota Press.

Potochnik, A. (2015). The diverse aims of science. Studies in History and Philosophy of Science. http://dx.doi.org/10.1016/j.shpsa.2015.05.008.

Rudner, R. (1953). The scientist qua scientist makes value judgments. Philosophy of Science, 20, 1-6

Stalnaker, R. C. (1984). Inquiry. Reprint edition 1987 ed. Cambridge: MIT Press

Steel, D. (2015). Acceptance, values, and probability. Studies in History and Philosophy of Science. http://dx.doi.org/10.1016/j.shpsa.2015.05.010. 
Ullmann-Margalit, E., \& Margalit, A. (1992). Holding true and holding as true. Synthese, 92(2), 167-187.

Velleman, J. D. (2000). "On the Aim of Belief," in The Possibility of Practical Reason. Oxford: Oxford University Press, 244-281.

Wray, K. B. (2001). Collective belief and acceptance. Synthese, 129, 319-333.

Daniel J. McKaughan

Philosophy Department, Boston College, 140 Commonwealth Avenue, Chestnut Hill, MA 02467, USA

E-mail address: daniel.mckaughan@bc.edu.
Kevin C. Elliott Lyman Briggs College, Michigan State University, East Lansing, MI 48825, USA

Department of Fisheries and Wildlife, Michigan State University, East Lansing, MI 48825, USA

Department of Philosophy, Michigan State University, East Lansing, MI

48825, USA

E-mail address: kce@msu.edu.

Please cite this article in press as: McKaughan, D. J., \& Elliott, K. C., Cognitive attitudes and values in science, Studies in History and Philosophy of Science (2015), http://dx.doi.org/10.1016/j.shpsa.2015.05.011 